\title{
APROXIMAÇÕES ENTRE INDICADORES DE ALFABETIZAÇÃO CIENTÍFICA E ATIVIDADE EXPERIMENTAL PROPOSTA EM LIVRO DIDÁTICO DOS ANOS INICIAIS
}

\section{ARTIGO ORIGINAL}

POLYDORO, Agda Melania ${ }^{1}$

MACIEL, Maria Delourdes ${ }^{2}$

POLYDORO, Agda Melania. Aproximações entre indicadores de alfabetização científica e atividade experimental proposta em livro didático dos anos iniciais. Revista Científica Multidisciplinar Núcleo do Conhecimento. Ano 04, Ed. 08, Vol. 03, pp. 84-109. Agosto de 2019. ISSN: 2448-0959, Link de acesso: https://www.nucleodoconhecimento.com.br/educacao/indicadores-dealfabetizacao

\section{RESUMO}

O artigo propõe a aplicação de uma Sequência Didática (SD), de uma atividade experimental que aborda o tema "Os sentidos", no Ensino de Ciências, associado ao conteúdo "Meu corpo percebe" do Livro Didático Aprender Juntos do 1aa do Ensino Fundamental. A concepção dessa pesquisa é nortear com base teórica e de material

\footnotetext{
${ }^{1}$ Mestranda em Ensino de Ciências e Matemática, Pós graduanda em Educação em Letramento e Alfabetização, Metodologias e Práticas Educativas e em Psicopedagogia Clínica e Institucional, graduada em Pedagogia.

2 Pós-Doutorado Em Educação Pela Pontifícia Universidade Católica De São Paulo (2006); Doutorado Em Educação (Psicologia Da Educação) Pela Pontifícia Universidade Católica De São Paulo (2001); Mestrado Em Educação (Supervisão E Currículo) Pela Pontifícia Universidade Católica De São Paulo (1995); Graduação Em Ciências Biológicas Pela Universidade Federal Do Rio Grande Do Sul (1976); Professora Titular I Na Universidade Cruzeiro Do Sul.
} 
didático, o planejamento da referida SD, ancorada na Alfabetização Científica (AC) e seus indicadores propostos por Sasseron (2008), dentro da perspectiva Ciência Tecnologia Sociedade (CTS), que trata conteúdos científicos integrados ao contexto social e tecnológico, abordados paralelamente à discussão de aspectos econômicos, políticos, sociais e éticos. Trata-se de uma análise exploratória e qualitativa, observamos documentos legais vigentes na educação sobre a disciplina do Ensino De Ciências e o uso do livro didático. O objetivo deste trabalho é propor uma reflexão sobre o papel das atividades experimentais dentro do Ensino de Ciência nos anos iniciais, com o intuito de incentivar a compreensão do processo de construção e o caráter social do conhecimento científico, aproximar essas visões para uma formação educacional que priorize a cidadania. No livro analisado conseguimos verificar que 0 tema é parte do currículo proposto pela Base Nacional Comum Curricular (BNCC, 2018), devendo ser melhor explorado pelo professor com o uso de outros recursos metodológicos que incentivem o aluno a ter uma formação crítica, reflexiva sobre conhecimentos, habilidades e valores necessários para tomar futuras decisões responsáveis sobre questões de CTS.

Palavras-Chave: Alfabetização científica, anos iniciais, atividades experimentais, ensino de ciências, sequência didática.

\section{INTRODUÇÃO}

No contexto de uma sociedade assinalada pela presença crescente da ciência e da tecnologia, tem-se a expectativa que a escola seja fonte de produção e difusão do conhecimento científico, haja vista, nossas crianças e jovens presentes no cotidiano da Educação Básica, oriundas de meios de comunicação e informação em que o conhecimento gerado de forma acelerada, com as ferramentas tecnológicas que se bem utilizadas, possibilitam o desenvolvimento intelectual desta população.

Considerando as informações advindas das mídias, a escola deve estar preparada e pode colaborar para que "o aluno adquira conhecimentos científicos e desenvolva capacidades de análise, interpretação, reflexão, comunicação, decisão, essenciais para o exercício da cidadania" (VIECHENESKI, 2013, p.19). 
Esta forma de viver o cotidiano dos estudantes está posta desde a mais tenra idade, isto é, nos anos iniciais do Ensino Fundamental, o que leva os educadores a refletir posturas que já não contemplam mais os educandos em virtude das "influências da associação entre ciência e tecnologia, logo, essas áreas são estudadas cada vez mais tentando entender os resultados desse momento atual" (SCHNORR, RODRIGUES, 2018).

A ciência entendida como um método científico, pode produzir conhecimentos, reconstruir e agregar aos existentes. Neste contexto, Schnorr e Rodrigues (2018, p. 47) propõem que pensar a "Educação e o Ensino de Ciências são campos que comtemplam essas temáticas e direcionam os modos como se entende os processos científicos e tecnológicos".

Os PCNs (Parâmetros Curriculares Nacionais) têm como proposta para o tema Ciências Naturais e Tecnologia, "oferecer aos educadores alguns elementos que thes permitam compreender as dimensões do fazer científico, sua relação de mão dupla com o tecnológico e o caráter não-neutro desses fazeres humanos"., neste sentido, reconhece-se neste documento a abordagem Ciência, Tecnologia e Sociedade para o Ensino de Ciências Naturais (BRASIL, 1997, p. 23).

Nos PCNs, o bloco Temático Recursos Tecnológicos, revela a preocupação da formação dos estudantes em relação a temas referentes a tecnologia e considera que o estudo dessas temáticas tem como objetivo "formar alunos capacitados para compreender e utilizar os recursos tecnológicos, cuja oferta e aplicação se ampliam significativamente na sociedade brasileira e mundial" (BRASIL, 1997, p. 40-41).

Nesta perspectiva, o Ensino de Ciências com enfoque Ciências, Tecnologia e Sociedade (CTS) valoriza o conhecimento que o estudante adquire em outros ambientes de aprendizagem, independente da faixa etária, possibilitando o desenvolvimento de senso crítico.

Soligo, Maciel e Guazzelli (2010) enfatizam que: 
O enfoque CTS defende que a escola, assim como outros espaços educativos, deve assumir o compromisso com uma didática das Ciências voltada para discutir as questões científico-tecnológicas que afetam a vida das pessoas, a vida em sociedade e as relações com o meio, tendo em vista a alfabetização científica para a cidadania. (SOLIGO, MACIEL, GUAZZELLI, 2010, p. 123).

O meio social em que os estudantes estão inseridos possibilita a exploração e compreensão das ciências, no percurso de suas vivências o que faculta a ação da escola para a inclusão da cultura científica, já nos anos iniciais, as questões ligadas à ciência e à tecnologia, conhecido internacionalmente como CTS evita a fragmentação do conhecimento das "áreas de saber, construindo uma nova visão curricular para as séries iniciais" (BRANDI, GURGEL, 2002, p. 113).

Segundo Chassot (2003), a ciência pode ser considerada como "uma linguagem para facilitar nossa leitura do mundo natural" e sabê-la como descrição do mundo natural nos ajuda a entendermos a nós mesmos, consequentemente, o ambiente que nos cerca, compreendê-la em sua representação natural, nos possibilita o entendimento do ambiente em que o homem está inserido e sua função no meio. Para o autor supracitado, "O mundo natural é aqui usado na acepção de nosso mundo orgânico e inorgânico, que forma o que chamamos de natureza" (CHASSOT, 2003, p. 93).

Para este autor, explicar o mundo natural significa elaborar um conjunto de métodos adquiridos e ao descrever a natureza estaria o sujeito fazendo Ciências, e o entendimento e a leitura desta descrição, poderíamos chamar de linguagem dita científica, assim, seria estar alfabetizado cientificamente. Ainda nesta dimensão, há um requisito a ser considerado pelo autor no que diz respeito a AC que deve "propiciar aos homens e mulheres uma alfabetização científica na perspectiva da inclusão social" (CHASSOT, 2003, p. 93).

O Ensino de Ciências, como área científica e tecnológica, é fértil para a promoção e propagação do conhecimento científico, e tem como possibilidade despertar nos estudantes habilidades de leitura e escrita, promovendo a AC, a fim de formar cidadãos críticos e envolvidos nas questões de cunho sociocientífico. 
Pesquisadores na área de Ensino de Ciências têm como proposta a observação de algumas habilidades demostradas durante o processo da AC em estudantes dos anos iniciais do Ensino Fundamental, expressando assim, potencialidades na promoção da construção do conhecimento da ciência nesta etapa escolar. Tais evidências são resultado de observações das habilidades solicitadas dos estudantes de forma a identificar a existência de indicadores de AC que revelam como os "estudantes trabalham durante a investigação de um problema e a discussão de temas das ciências fornece elementos para se dizer que a Alfabetização Científica está em processo de desenvolvimento para eles" (SASSERON, 2008, p. 68).

Sasseron (2008), afirma que para se construir a AC em sala de aula devemos utilizar os indicadores de AC que seriam também competências próprias do fazer científico, reforçando a ideia do ensino de Ciências através de atividades investigativas, contando com a curiosidade das crianças nesta fase educacional e estimulando e reforçando este interesse em pesquisar, refletir, tornar-se um cidadão crítico.

Neste sentido, este artigo tem como objetivo propor uma reflexão sobre o papel das atividades experimentais dentro do Ensino de Ciências, com o intuito de incentivar a compreensão do processo de construção e o caráter social do conhecimento científico, aproximar essas visões, para uma formação educacional que priorize a cidadania.

Para atingir este objetivo a professora da classe pesquisada aplicou uma sequência didática (SD) a fim de averiguar se atividades experimentais em livros didáticos possuem características pedagógicas que facilitem a AC em alunos dos anos iniciais. O uso da SD nesta pesquisa deve-se ao fato de serem "atividades ordenadas, estruturadas e articuladas para a realização de certos objetivos educacionais, que têm um princípio e um fim conhecidos tanto pelos professores como pelos alunos" (ZABALA, 1998, p. 18).

Esta SD foi elaborada a partir de atividade experimental do Livro didático utilizado em aulas de ciências em uma turma do primeiro ano do Ensino Fundamental para 
posterior averiguação, observando e discussão de quais os indicadores de AC que possibilitaram o processo com os estudantes pesquisados.

\subsection{A SEQUÊNCIA DIDÁTICA NO ENSINO DE CIÊNCIAS E SUA CONTRIBUIÇÃO NO PROCESSO DE ALFABETIZAÇÃO CIENTÍFICA}

Frente ao crescente desenvolvimento tecnológico e científico presente em nosso cotidiano, faz-se necessário entender as implicações decorrentes desta evolução e suas consequências para a sociedade, assim as aulas de ciências com enfoque Ciência Tecnologia e Sociedade (CTS) possibilita trabalhar com os alunos os avanços tecnológicos com os conteúdos proporcionando maior significado ao que será trabalhado com os educandos (FAGUNDES et al. 2009).

Nesta perspectiva, os conteúdos tratados em aulas de Ciências nos primeiros Anos do Ensino Fundamental devem estar envolvidos com os problemas do cotidiano, vinculados às questões sociocientificas de forma a proporcionar discussões objetivando a formação crítica com os estudantes desde sua tenra idade.

Os documentos oficiais como, por exemplo, os Parâmetros Curriculares Nacionais, apresentam o ensino de Ciências com o enfoque Ciências, Tecnologia e Sociedade (CTS), e sua contribuição educativa para questões sociais, políticas, ambientais, econômicas, éticas e de saúde pública, temas com relevância para apropriação de formação para a cidadania no Ensino de Ciências. Temas pertinentes que desenvolvam o pensamento crítico e instrumentalizador na tomada de decisões conscientes para sua própria saúde e para o meio ambiente.

Os PCNs preconizam para o ensino de ciências nos anos iniciais, a criança a formação para cidadania, assim este documento estabelece que:

A criança não é cidadã do futuro, mas já é cidadã hoje, e, nesse sentido, conhecer ciência é ampliar a sua possibilidade presente de participação social e viabilizar sua capacidade plena de participação social no futuro (BRASIL, 1997, p. 22-23). 
A faixa etária dos alunos encontrada nesta etapa da Educação Básica, isto é, nos anos iniciais, viabiliza tratar o conhecimento científico de forma a ampliar a informação, objetivando a formação mais eficiente em virtude de ser essencial para nosso desenvolvimento de uma sociedade e sua dependência destes avanços para sua difusão da ciência. "Aumentar o nível de entendimento público da Ciência é hoje uma necessidade, não só como um prazer intelectual, mas também como uma necessidade de sobrevivência do homem" (LORENZETTI, DELIZOICOV, 2001.p. 5).

Este artigo faz parte de uma pesquisa de Mestrado em andamento que tem como objetivo averiguar atividades experimentais presentes em livros didáticos do primeiro ano ao quinto ano do Ensino Fundamental (Anos Iniciais). A escolha da aplicação da SD numa atividade experimental, do livro de Ciências, foi principalmente devida à melhor compreensão prática dos alunos, conforme Vasconcelos e Souto (2003):

O livro de Ciências deve propiciar ao aluno uma compreensão científica, filosófica e estética de sua realidade, oferecendo suporte no processo de formação dos indivíduos/cidadãos. Consequentemente, deve ser um instrumento capaz de promover a reflexão sobre os múltiplos aspectos da realidade e estimular a capacidade investigativa do aluno para que ele assuma a condição de agente na construção do seu conhecimento (VASCONCELOS, SOUTO, 2003, p. 4)

Segundo Krasilchik e Marandino (2004), um dos aspectos importantes das atividades experimentais e práticas é fomentar nos alunos condições para interpretar os fenômenos, manipular e vivenciar novos recursos com a participação de todos.

Podemos justificar no presente artigo, que a discussão sobre atividades experimentais, de suma importância, deve ser colocada em todos os níveis educacionais, inclusive nos anos iniciais e principalmente na formação de professores.

A nossa responsabilidade maior no ensinar Ciência é procurar que nossos alunos e alunas se transformem, com o ensino que fazemos, em homens e mulheres mais críticos. Sonhamos que, com nosso fazer Educação, os estudantes possam tornar-se agentes de transformações - para melhor - do mundo em que vivemos. (CHASSOT, 2003, p. 31).

As atividades experimentais no ensino de ciências nos anos iniciais, mesmo para um aluno em processo de letramento, realiza a função de juntar teoria à prática, as 
crianças já têm em si a curiosidade natural da faixa etária e o interesse por assuntos tecnológicos, cotidianos e científicos. Isto intensifica quando a proposta tem temas atrativos em atividades dinâmicas, ou seja, a proposta de um experimento prático e real, é um facilitador, garantia de uma situação concreta de ensino e aprendizagem, que nem sempre acontecem nas aulas regulares.

Para Lorenzetti e Delizoicov (2001), o Ensino de Ciências nos anos iniciais, as atividades abertas, reflexivas e investigativas nas quais os alunos desempenhem o raciocínio lógico e a construção de conhecimento significativo, entendam a função de pesquisa individual e coletiva em sala. A AC compreendida "[...] como o processo pelo qual a linguagem das Ciências Naturais adquire significados, constituindo-se um meio para o indivíduo ampliar o seu universo de conhecimento, a sua cultura, como cidadão inserido na sociedade" (LORENZETTI, DELIZOICOV, 2001, p. 8-9).

Nesta perspectiva, em atendimento no processo de AC e construção do conhecimento nos anos iniciais, a Sequência Didática (SD) tem como proposta facilitar e dar significado às atividades experimentais, tendo em vista um processo interativo entre educando/educando e educador/educando, mesmo que os alunos ainda não dominem o processo de codificação da leitura e escrita.

Zabala (2010) preconiza que o convívio entre professor e alunos e estes com seus pares, tem importância e influência no processo de aprendizagem para que a aquisição do conhecimento se defina, as atividades experimentais favorecem esta prática de socialização e interação.

A SD tem como premissa a comunicação oral e ou escrita, entre os estudantes que não dominam sozinhos determinados gêneros textuais, consequentemente, seu uso como estratégia, possibilita superar os obstáculos por ser uma atividade orientada, direcionada de forma sistematizada objetivando o ensino da leitura, da escrita, da oralidade, proporcionando fases de organização do processo educacional. (BARBOSA, 2011). 
Para Zabala (1998), a organização de uma SD tem a característica de valorizar as atividades em ordem significativa para uma reflexão das etapas, permitindo o "planejamento, aplicação e avaliação" (ZABALA, 1998, p.18).

Unidade didática, unidade de programação, unidade de intervenção pedagógica quando se refere a sequências de atividades estruturadas para a realização de certos objetivos educacionais determinados. Estas unidades têm como virtudes de manter o caráter unitário e reunir toda a complexidade da prática, ao mesmo tempo que são instrumentos que permitem incluir as três fases de toda intervenção reflexiva: planejamento, aplicação e avaliação (ZABALA, 1998, p. 18).

Zabala (1998), propõe a utilização do livro didático em sua aula, porém não pode depender exclusivamente deles, visto que o trabalho pedagógico deve ter como proposta o uso de instrumentos e recursos que possibilitem na tarefa de ensinar "mas são necessários materiais que estejam a serviço de nossas propostas didáticas e não o contrário; que não suplantem a dimensão estratégica e criativa dos professores, mas que a incentivem" (ZABALA 1998, p. 175).

O livro didático pode e deve ser utilizado como recurso didático, pois apresenta textos de apoio, links ou sites relacionados ao tema que apresenta, e sugere ainda atividades experimentais facilitando a investigação, comunicação entre conceitos, ações manuais, entre outras possibilidades exploratórias à disposição do professor e da turma.

O conteúdo do livro didático valoriza a socialização em sala de aula, propõe a mediação entre professor/aluno, intermediando situações de respeito e colaboração ao próximo, trabalho em grupo, organização, curiosidade, pensamento crítico, criatividade entre outras. "O ensino acontece através da atividade mental construtiva desse aluno, que manipula, explora, escuta, lê, faz perguntas e expõe ideias" (CARVALHO 2009, p.35).

Díaz, Alonso e Mas (2003), afirmam que no Ensino de Ciências a finalidade mais importante hoje é a AC, pois propõe conhecimentos científicos localizados socialmente, traz benefícios práticos pessoais e sociais aos alunos, permitindo, 
criando e possibilitando condições para tomada de decisões referentes a problemas que os afligem, enfim, um aprendizado, uma educação para a vida.

Para identificar a AC, Sasseron (2008) propõe que no planejamento das aulas devemos focar nos três eixos estruturantes do desenvolvimento das habilidades de CTS, que seriam: a) compreensão de termos, conceitos e conhecimentos científicos fundamentais, b) compreensão da natureza das Ciências e dos fatores éticos e políticos que circundam sua prática, e c) o entendimento das relações existentes entre CTS e Meio Ambiente. A autora ainda pautou indicadores (Quadro 1), cuja função é classificar as ações do desenvolvimento dos alunos em sala de aula para diagnosticar se está havendo AC durante o processo de aprendizagem.

Quadro 1 - Indicadores de AC propostos por Sasseron (2008)

\begin{tabular}{|c|c|}
\hline $\begin{array}{l}\text { Indicador de } \\
\text { Alfabetização } \\
\text { Cientifica }\end{array}$ & $\begin{array}{l}\text { Habilidades Desenvolvidas Durante o Processo da } \\
\text { Alfabetização Científica }\end{array}$ \\
\hline $\begin{array}{l}\text { Seriação } \\
\text { Informações }\end{array}$ & $\begin{array}{l}\text { Está ligada ao estabelecimento de bases para a ação } \\
\text { investigativa. Não prevê, necessariamente, uma ordem que } \\
\text { deva ser estabelecida para as informações: pode ser uma lista } \\
\text { ou uma relação dos dados trabalhados ou com os quais se vá } \\
\text { trabalhar. }\end{array}$ \\
\hline $\begin{array}{l}\text { Organização de } \\
\text { Informação }\end{array}$ & $\begin{array}{l}\text { Surge quando se procura preparar os dados existentes sobre } \\
\text { o problema investigado. Este indicador pode ser encontrado } \\
\text { durante o arranjo das informações novas ou já elencadas } \\
\text { anteriormente e ocorre tanto no início da proposição de um } \\
\text { tema quanto na retomada de uma questão, quando ideias são } \\
\text { relembradas. }\end{array}$ \\
\hline $\begin{array}{l}\text { Classificação de } \\
\text { Informações }\end{array}$ & $\begin{array}{l}\text { Aparece quando se busca estabelecer características para os } \\
\text { dados obtidos. Por vezes, ao se classificar as informações, } \\
\text { elas podem ser apresentadas conforme uma hierarquia, mas } \\
\text { o aparecimento desta hierarquia não é condição sine qua non }\end{array}$ \\
\hline
\end{tabular}




\begin{tabular}{|l|l|}
\hline Raciocínio & $\begin{array}{l}\text { para a classificação de informações. Caracteriza-se por ser um } \\
\text { indicador voltado para a ordenação dos elementos com os } \\
\text { quais se trabalha. }\end{array}$ \\
\hline Lógico & $\begin{array}{l}\text { Compreende o modo como às ideias são desenvolvidas e } \\
\text { apresentadas e está diretamente relacionada à forma como o } \\
\text { pensamento é exposto. }\end{array}$ \\
\hline Proporciocínio & $\begin{array}{l}\text { Como o raciocínio lógico, o raciocínio proporcional dá conta de } \\
\text { mostrar como se estrutura o pensamento, e refere-se também } \\
\text { à maneira como variáveis tem relações entre si, ilustrando a } \\
\text { interdependência que pode existir entre elas }\end{array}$ \\
\hline Hevantamenteses & $\begin{array}{l}\text { Aponta instantes em que são alçadas suposições acerca de } \\
\text { certo tema. Este levantamento de hipóteses pode surgir tanto } \\
\text { da forma de uma afirmação como sendo uma pergunta (atitude } \\
\text { muito usada entre os cientistas quando se defrontam com um } \\
\text { problema). }\end{array}$ \\
\hline Teste & $\begin{array}{l}\text { Trata-se das etapas em que as suposições anteriormente } \\
\text { levantadas são colocadas à prova. Pode ocorrer tanto diante } \\
\text { da manipulação direta de objetos quanto no nível das ideias, } \\
\text { quando o teste é feito por meio de atividades de pensamento } \\
\text { baseadas em conhecimentos anteriores. A }\end{array}$ \\
\hline Previsão & $\begin{array}{l}\text { Aparece quando, em uma afirmação qualquer proferida, lança } \\
\text { mão de uma garantia para o que é proposto. Isso faz com que } \\
\text { a afirmação ganhe aval, tornando mais segura. } \\
\text { É explicitado quando se afirma uma ação e/ou fenômeno que } \\
\text { sucede associado a certos acontecimentos. }\end{array}$ \\
\hline $\begin{array}{l}\text { Surge quando se busca relacionar informações e hipóteses já } \\
\text { levantadas. Normalmente a explicação é acompanhada de } \\
\text { uma justificativa e de uma previsão, mas é possível encontrar } \\
\text { explicações que não recebem estas garantias. Mostram-se, } \\
\text { pois, explicações ainda em fase de construção que certamente } \\
\text { receberão maior autenticidade ao longo das discussões. }\end{array}$ \\
\hline Justiva
\end{tabular}


Fonte: Adaptado de Sasseron (2008, p.335)

As aulas de Ciências voltadas à $\mathrm{AC}$, tendo como referencial teórico os indicadores de AC propostos por Sasseron, quando empregados nas atividades experimentais dos Livros Didáticos, promovem desafios, construção e desconstrução de hipóteses e ideias, argumentação e resolução de problemas, entre outras habilidades, fomentadas a partir do trabalho coletivo e colaborativo em sala, para que aluno não dissocie o conhecimento escolar da sua realidade e tenha sua aprendizagem assegurada para a vida.

Sobre a escolha do livro didático, esta deve ser feita com muita seriedade e rigor. Segundo Nuñez (2000), a seleção dos livros didáticos a serem utilizados constitui uma tarefa de relevância para o sucesso de aprendizagem dos alunos.

Por isso, a importância de procurar critérios específicos para os contextos dados, que possibilitem ao professor participar na avaliação dos livros didáticos. Geralmente os critérios estabelecidos, são gerados em diferentes instâncias de análises, das quais os professores, como coletivos, representam a instância que deve tomar as decisões mais apropriadas, pensando no alunado com as quais trabalham. A seleção dos livros didáticos não deve excluir os professores como construtores ativos de saberes que desenvolvem essa importante competência profissional (NUÑEZ et al, 2000, p. 02).

A escolha do livro didático com a validação do professor, hoje é um grande avanço, pois no Ensino de Ciências dos Anos Iniciais, o livro é referência. Os professores destacam sua função em sala de aula, consideram o livro como um importante recurso auxiliar para romper com a metodologia "stank" de memorização e cópias mecânicas, acúmulo de informação sem uma finalidade educativa evidente. $O$ olhar do professor oferece uma escolha coerente à proposta de ensino e às metodologias a serem aplicadas, favorecendo um tipo de uso que estimule a investigação e a pesquisa de fenômenos; que trabalhe a Ciência para o bem; que atenda as demandas e expectativas da realidade social; que contribua para a formação do cidadão. 


\section{METODOLOGIA}

Neste artigo, a metodologia utilizada foi a pesquisa descritiva, que tem como função o registro, a interpretação, a análise dos fatos do mundo físico sem a interferência do pesquisador e tem por finalidade a observar, registrar e analisar os fenômenos sem adentrar no mérito dos conteúdos (BARROS, LEHFELD, 2007).

Este tipo de pesquisa permite o relato de experiência, o que suscitou apresentação desta averiguação, na qual a pesquisadora faz uma discussão e análise de uma atividade experimental retirada do livro didático em uma turma de $1^{\circ}$ ano do Ensino Fundamental.

Para a condução da SD a pesquisadora aplicou uma atividade experimental sobre os sentidos do corpo humano, cujo capítulo do livro é intitulado "Meu Corpo Percebe", e a atividade chama-se "Identificando objetos pelo Tato" presente no livro utilizado como recurso pedagógico em suas aulas.

Para que atingisse seu objetivo, a pesquisadora/professora, utilizou uma sequência didática que teve como intenção verificar aproximações entre a atividade experimental e o processo de AC, analisando os possíveis indicadores de alfabetização Científica (SASSERON 2008) presentes na aplicação.

\section{RESULTADOS E ANÁLISES}

As atividades experimentais nos anos iniciais valorizam a compreensão da natureza da ciência e a importância dos referenciais epistemológicos na prática pedagógica. Segundo Moraes (1998), as atividades experimentais podem ter seu desenvolvimento em diferentes concepções: demonstrativa, empirista - indutivista, dedutivista relacionista ou construtivista. Atividades demonstrativas, segundo alguns autores, como Gaspar e Monteiro (2005), Araújo e Abib (2003), Pinho e Alves (2000), são de caráter motivacional, agradável e facilitam a participação dos alunos e podem acontecer na própria sala de aula, tornando-se um laboratório. Já nas empiristas - 
indutivista, refere-se desde a parte sensorial, seguindo um regramento estabelecido, a obtenção de dados até as observações e previsões durante toda a atividade.

E na dedutivista-relacionista, o conhecimento prévio e a observação influenciam diretamente na coerência da metodologia e construção do conhecimento. Nas atividades experimentais construtivistas, deve-se contar características como a dinâmica e interatividade, promovendo o desenvolvimento das estruturas de pensamento, argumentação e o raciocínio lógico "no qual contribui para desenvolver um raciocínio prático no que se refere a um comportamento interpretativo próprio da condição humana" (ROSITO, 2003, p.200).

Nesta perspectiva uma SD precisa de planejamento, organização em sala de aula, feita em grupos pequenos, o professor deve circular em sala, ser acessível, ajudar no entendimento do experimento, realizar comparações, reflexões e argumentos que envolvam os alunos na atividade, tornando a aula proveitosa e interessante.

Nos anos iniciais, quando falamos que é aula de ciências, eles já ficam animados e curiosos, em se tratando de atividade experimental, devemos reforçar conceitos já existentes. "Para o espírito científico, todo conhecimento é resposta a uma pergunta. Se não há pergunta, não pode haver conhecimento científico. Nada é evidente. Nada é gratuito. Tudo é construído" (BACHELARD, 1996, p.18).

As Diretrizes Curriculares Nacionais para a Educação Básica (2013 p. 91) determinam as práticas pedagógicas devem possibilitar a criança viver "experiências e compreensão do mundo feita pela totalidade de seus sentidos, no conhecimento que constrói na relação intrínseca entre razão e emoção, expressão corporal e verbal, experimentação prática e elaboração conceitual". 


\subsection{DESENVOLVIMENTO DE ATIVIDADE EXPERIMENTAL ATRAVÉS DE UMA SEQUÊNCIA DIDÁTICA PARA IDENTIFICAÇÃO DOS INDICADORES DE ALFABETIZAÇÃO CIENTÍFICA}

A atividade experimental, intitulada "Identificando Objetos Pelo Tato" foi aplicado através de uma SD em quatro aulas divididas de 45 minutos em momentos a saber:

$1^{\underline{a}}$ aulas: Organização dos alunos em grupos, levantamento dos conhecimentos prévios através de problematização conforme o quadro 02.

No transcorrer das discussões, os alunos se mostraram bastante eufóricos, com uma participação ativa e quando havia discordância, cada aluno argumentava como por exemplo:

Quadro 02 - Levantamentos Prévios / Explorando o Tema (A1: aluno 1, A2: aluno 2... e assim sucessivamente)

\begin{tabular}{|c|c|}
\hline Questões (Problematizando) & $\begin{array}{l}\text { Discussão oral, momento de } \\
\text { reconhecimento dos conhecimentos } \\
\text { prévios dos alunos }\end{array}$ \\
\hline $\begin{array}{l}\text { a) Vocês sabem o que significa a } \\
\text { palavra: textura? Me diga agora } \\
\text { qual a textura de sua roupa, } \\
\text { calça, blusa, meia...? } \\
\text { (Professora) }\end{array}$ & $\begin{array}{l}\text { (A1) Minha calça é lisa, minha blusa é } \\
\text { grossa... (A2) Minha blusa é de uma linha feita } \\
\text { de furinhos (tipo crochê) ... } \\
\text { (A3) A minha meia é fininha e lisinha... } \\
\text { (A4) Prô, minha meia é cheia de bolinhas, vem } \\
\text { ver... (A5) Minha meia é de lã bem grossa, lã } \\
\text { é quentinha. }\end{array}$ \\
\hline $\begin{array}{l}\text { b) Qual a parte de seu corpo que } \\
\text { você sente que a água está } \\
\text { quente ou fria? (Professora) }\end{array}$ & $\begin{array}{l}\text { (A1) Minhas mãos, minhas costas (quanto } \\
\text { tomo banho minhas costas ficam vermelhas, } \\
\text { minha mãe disse que é porque a água está } \\
\text { muito quente... (A2) Meu pé (coloco meu pé }\end{array}$ \\
\hline
\end{tabular}


c) É possivel reconhecer objetos apenas pelo tato? (Professora)

primeiro para molhar quando tomo banho) ... (A3) As vezes a água cai primeiro no meu corpo, ah então na pele toda né!

(A1) Não, eu posso saber que objeto é pelo cheiro, quando minha tia frita bife, eu sei o cheiro... (A2) Eu sinto cheiro (aff) de cândida quando minha mãe tá usando, ela fala que é perigoso e que "nóis" tem que saber ler papéis (rótulos)...

(A3) Ouvir algo cair, por exemplo um copo quando cai e quebra a gente usa o ouvido né prô?

d) Uma blusa mais grossa é mais (A1) É mais quente... (A2) Blusa fina não quente do que uma blusa mais fina? $E$ qual a blusa que esquenta? Respondam: É você ou a blusa que é quente? (Professora) esquenta, porque é fina...

(A3) Quando faz frio e eu não trago blusa, fico encolhido, aí não sinto tanto frio...

(A4) Eu sou quente, mas a blusa também é... (A5) A blusa pode ser quente sem ser grossa... (A6) Eu senti febre e meu corpo esquentou daí tomei remédio e sarei...

Fonte: Autor.

A textura das blusas, o tipo de tecido como algodão, helanca e a blusa artesanal, por apresentar pontos que davam certo relevo e o tipo de linha. Houve momentos em que o argumento estava em quem produziu e como era produzido, visto que a blusa de crochê foi feita pela avó.

A questão da água quente e fria, este momento foi de muito espanto, já que no meio da discussão um dos alunos disse "então a pele toda é tato", neste momento a professora propôs a seguinte questão: alguém sabia a função da pele, um dos alunos 
respondeu que era para os órgãos não caírem e outro para proteção das "coisas" do ambiente.

A questão do reconhecimento dos objetos, houve comparação com os órgãos dos sentidos, como olfato, visão e audição, como exemplos disseram que ao ouvir um copo cair, sabem que era um vidro, que na aula de paladar, sentiu que era laranja, que tinha sal no alface entre outros comentários.

$\mathrm{Na}$ questão da blusa, houve uma retomada da questão sobre textura e sobre, tecido grosso, fino, furadinho, sem furo, tecido da jaqueta do colega e se a pele, uma questão interessante entrou na discussão, uma das alunas havia ficado doente na semana anterior, o que motivou sua falta, a mesma comentou que tinha tido febre, neste momento, a professora interviu com uma explicação porque o corpo aumenta de temperatura e temos a chamada "febre".

Esta primeira aula, trouxe fatos do cotidiano para que os alunos usassem e assim pudessem defender suas ideias, foi uma aula descontraída, rica em informação e interação entre todos.

Pôde-se perceber, que a alfabetização científica esteve em processo, porém, de forma verbal. Analisamos alguns indicadores com as respostas, presentes no quadro 03.

Observou-se que os indicadores de AC (SASSERON, 2008, p.335), Explicação e Justificativa, estiveram em processo, uma vez que os alunos, ao explicitar seus argumentos utilizaram-se de seus conhecimentos prévios, e as informações reveladas nos diálogos foram advindas das características dos materiais, valendo-se também dos fatos existentes em falas dos colegas e de situações do cotidiano.

O indicador Levantamento de Hipótese esteve presente em apenas uma das questões de forma mais explicita, visto que houve questionamento, pergunta por dedução, observação ou mesmo afirmação. 
Quadro 03 - Atividade: reconhecimento dos objetos através da textura

\begin{tabular}{|c|c|c|}
\hline № & Respostas dos alunos & $\begin{array}{l}\text { Indicadores de } \\
\text { AC }\end{array}$ \\
\hline 01 & $\begin{array}{l}\text { Lisa, grossa, tecido com furinhos, meia com bolinhas, linha } \\
\text { bem grossa }\end{array}$ & $\begin{array}{l}\text { Justificativa } \\
\text { Explicação }\end{array}$ \\
\hline 02 & Minhas mãos, minhas costas, meu pé, meu corpo todo & $\begin{array}{l}\text { Justificativa } \\
\text { Explicação }\end{array}$ \\
\hline 03 & Pelo cheiro, leitura do rotulo, ouvir algo cair, & $\begin{array}{l}\text { Explicação } \\
\text { Justificativa }\end{array}$ \\
\hline 04 & $\begin{array}{l}\text { Mais quente, a Blusa não é quente porque é fina, quando } \\
\text { sinto frio e não tenho blusa, me encolho para diminuir o frio, } \\
\text { a blusa é quente, mas eu também sou, a blusa pode ser } \\
\text { quente sem ser grossa, eu senti febre e meu corpo todo ficou } \\
\text { quente }\end{array}$ & $\begin{array}{l}\text { Explicação } \\
\text { Justificativa } \\
\text { Levantamento } \\
\text { Hipótese } \\
\text { Teste de } \\
\text { Hipótese }\end{array}$ \\
\hline
\end{tabular}

Fonte: Autor.

Quanto aos questionamentos referentes a pele como órgão do tato e sobre a febre, notou-se a presença do indicador Teste de Hipótese, visto que os alunos participaram ativamente da atividade experimental e de ideias baseadas em conhecimentos anteriores.

$\mathrm{Na}$ aula de número 02, teve início com a distribuição dos sacos surpresas pela professora que solicitou que cada aluno em seu grupo, sem olhar, introduzisse a mão e pegasse apenas um objeto, e tentasse adivinhar o que era, feito isto o aluno disse qual seria o objeto e os critérios que utilizou para o reconhecimento do mesmo. $\mathrm{E}$ 
assim, todos os alunos passaram pela experiência e verbalizaram os critérios. Os objetos eram variados e de diversas texturas, formas e temperaturas.

Desta forma, houve uma recuperação do conteúdo visto na aula anterior e uma motivação para que pudessem assistir aos filmes dos canais do Youtube, sobre os sentidos e o funcionamento dos órgãos relacionados a eles e de como estas informações percorrem o corpo até o sistema nervoso. Falamos neste momento também sobre emoções e outros desdobramentos também.

Muitos outros exemplos foram dados quando se trata do cotidiano, as informações contidas nas falas, demostraram que mesmo sem haver a escrita adequada, os alunos desenvolveram a alfabetização científica no processo (Quadro 04).

Quadro 04 - Pós filme: Discussão, dúvidas e deduções realizadas pelos alunos

\section{Fala dos Alunos}

(A1) Então quando eu sinto cheiros, na minha cabeça, o meu celebro recebe os cheiros?

(A2) O que sinto na pele corre pelo corpo até chegar na cabeça?

(A3) Eu tenho medo de barata, então quando eu vejo eu grito, passa pelos olhos depois chega na cabeça, isto é, no cérebro?
Indicadores de Alfabetização Científica em processo

Organização das informações: indicador de organização dos conteúdos e retomada de conceitos anteriores

Classificação de informação:
organização dos dados que estão relacionados as informações dos filmes

Raciocínio logico: A compreensão das ideias tratadas no filme e a organização do pensamento para a exposição do entendimento

Fonte: Autor.

Terminada a discussão, os alunos retomaram os desenho dos objetos que retiraram do saquinho, colocando as características deles e que critério utilizaram para o reconhecimento. Na lousa a professora havia escrito sobre os cinco sentidos e o nome deles: tato, olfato, audição, paladar e visão. 
A aula de número 03 iniciou com a exposição do filme editado "Divertida Mente", que teve como objetivo trabalhar sensações como medo, tristeza, nojo, alegria, raiva, medo, as questões que motivaram a discussão pós filme.

Formou-se uma roda de conversa, verificou-se que $97 \%$ dos alunos já haviam assistido o filme em suas casas, as discussões foram exemplificadas com situações do que cada um sentia em relação as sensações que a protagonista do filme sentia também, a questão da resiliência, e a necessidade de se trabalhar o olhar que cada um deve ter com o outro.

Nesta aula, o indicador de AC (Sasseron, 2008), demostrado nesta atividade foi a Seriação de Informações, este indicador não tem o propósito de estabelecer critérios rígidos de metodologia e arranjos. Este indicador foi demostrado pelas falas, uma vez que o repertório usado pelos alunos é a linguagem verbal (oralidade).

Para o encerramento, solicitou-se que os alunos desenhassem "emojis" que expressam as emoções de maneira tecnológica, via celular em aplicativos de conversação, pedimos para que relacionassem os desenhos aos sentimentos e sensações propostos no filme e estendemos para questões presentes em nosso cotidiano, como: com que carinha você acorda? No horário da refeição, qual a carinha que você faz? Quando se machuca? Quando dorme? Entre outras perguntas que foram surgindo na aula, propostas por eles mesmos.

A aula de número 04 iniciou com a exposição oral dos trabalhos em grupo, isto é, cada grupo apresentou para o restante da classe seus desenhos e posterior a isto, colaram em um papel pardo para exposição futura.

No segundo momento, fechamento com perguntas para sanar dúvidas, iniciou a construção do livrinho sobre "os sentidos" em MDF, devendo este também ser exposto em apresentações dos trabalhos da escola, que acontece na Feira do Conhecimento.

Aqui, o indicador que evidenciou o processo de AC, proposto por Sasseron (2008) foi o indicador da Previsão, por constatar que durante a confecção dos livrinhos, houve um aproveitamento dos conceitos desenvolvidos durante a atividade proposta. 


\section{CONSIDERAÇÕES FINAIS}

As atividades experimentais nos anos iniciais atraem a atenção dos alunos para o Ensino de Ciências, despertando o interesse e a curiosidade, tornando-se uma metodologia muito eficiente, pois por se tratar de uma aula prática e aberta, as crianças desenvolvem o pensamento para a determinada atividade, mas que transcende na construção de conhecimento, visto como uma ferramenta motivadora (GONÇALVES, 2009).

"Ensinar Ciências é propiciar aos alunos situações de aprendizagem" (GUIMARÃES, 2009, p. 12/13). Devemos planejar as aulas de acordo com o contexto social, articular com conteúdos que propiciem significado aos alunos, potencializando e possibilitando aos alunos a formulação de hipóteses, fomentando nos alunos o uso da Ciência no dia a dia, relacionando ciência e sociedade.

Utilizando-se da sequência didática sobre os sentidos, proposta nesta pesquisa, observou-se que as SD são atividades planejadas dentro de um eixo temático, ordenadas e articuladas com objetivos educacionais que permitem em sua prática a possibilidade de observação dos indivíduos envolvidos (ZABALA 1998).

No que diz respeito aos conceitos estruturados em aulas de Ciências, com enfoque CTS, a SD propõe um envolvimento dos alunos, tendo em vista o tema, "Identificando objetos pelo Tato", por estar diretamente relacionado as sensações e resposta de seu corpo no ambiente que o cercam, estimulando a investigação através da problematização do cotidiano, trazendo discussões que levam a explicações baseadas em fatos vividos diariamente, as hipóteses, são confrontadas com as respostas do grupo, desenvolvendo assim, o diálogo baseado em justificativas que permeiam o universo dos alunos.

A aplicação desta SD promoveu a aprendizagem e desenvolvimento da AC, na medida em que a organização contempla a participação ativa do aluno, o levantamento do conhecimento prévio, durante a realização de atividades programadas, facilitando assim a construção de conceitos científicos, partindo do 
vivencia, com o uso de materiais simples, porém que contemplam a comunicação e a construção do conhecimento científico demostrado através da linguagem oral, escrita.

Através desta Sequência Didática, pode-se observar que os indicadores de AC estiveram presentes, o que demostra que a Alfabetização Científica deu-se durante todo o processo, o currículo está adequado ao Livro didático, que está preconizado na Base Nacional Comum Curricular (BNCC), fomentar alunos capazes de ser pessoas com conhecimentos científicos, que atuem criticamente na sociedade, compreendam sua realidade.

De acordo com a BNCC, a AC tem como objetivo formativo no Ensino de Ciências, que o aluno tenha "capacidade de compreender e interpretar o mundo (natural, social e tecnológico), mas também de transformá-lo com base nos aportes teóricos e processuais da Ciência" (BRASIL, 2018).

Com a finalidade de compartilhar saberes docentes, inclusive com outras áreas de conhecimento, o artigo em questão é parte de uma pesquisa de mestrado em andamento e produto educacional, elaborado através do livrinho em PDF, demostrando diversas texturas e possibilidades de interação em sala de aula, provando a capacitação de alunos dos anos iniciais em suas habilidades e qualificações no processo de alfabetização científica.

As crianças têm a curiosidade e a disponibilidade para procurar respostas, para desenvolver situações de aprendizagens através de aulas mais dinâmicas, a partir da experimentação, levantar hipóteses e desafiar o raciocínio. A SD com a atividade experimental torna a aula mais intensa, participativa e proveitosa, teve muitos desdobramentos produtivos devido à resolução de problemas e a outras habilidades desenvolvidas.

\section{REFERÊNCIAS}

BARROS, A.; LEHFELD, N. Fundamentos de metodologia científica. 3. ed. São Paulo: Pearson Prentice Hall, 2007. 
BRANDI, A.; GURGEL, C. A Alfabetização Científica e o processo de ler e escrever em séries iniciais: emergências de um estudo de investigação. Ciência \& Educação, v. 8, n. 1, p. 113-12, 2002.

BRASIL. Secretaria de Ensino Fundamental. Parâmetros Curriculares Nacionais. Brasília, MEC, 1997. http://portal.mec.gov.br/seb/arquivos/pdf/ivro01.pdfAcesso 11/10/2018.

. Diretrizes Curriculares Nacionais Gerais da Educação Básica / Ministério da Educação. Secretaria de Educação Básica. Diretoria de Currículos e Educação Integral. Brasília: MEC, SEB, DICEI, 2013. http://portal.mec.gov.br/Acesso 11/10/2018.

- Base Nacional Comum Curricular: Educação Básica. Ministério da Educação. 2018.http://basenacionalcomum.mec.gov.br/images/BNCC _versaofinal_site.pdfAcesso em 10/11/2018.

CARVALHO, A. Critérios estruturantes para o ensino das Ciências. In: CARVALHO, A. (Org.). Ensino de Ciências: Unindo a Pesquisa e Prática. São Paulo: Pioneira Thomson Learning, 2004. p. 1-17.

CHASSOT, A. Alfabetização científica: uma possibilidade para a inclusão social. Revista Brasileira de Educação, São Paulo, v. 23, n. 22, p. 89-100, 2003. Disponível em: <http://www.scielo.br/pdf/rbedu/n22/n22a09.pdf>. Acesso em: 13/01/2019

CHASSOT, A. Alfabetização Científica: questões e desafios para a educação. 7 ed. ljuí: Unijuí, 2003. 344p.

DELIZOICOV, D.; ANGOTTI, J.; PERNAMBUCO, M. Ensino de Ciências: Fundamentos e Métodos. 4 eds. São Paulo: Cortez, 2011. 366p.

DÍAZ, J.; ALONSO, A.; MAS, M. "Papel de la Educación CTS en una Alfabetización Científica y Tecnológica para todas las personas" Revista Eletrônica de Enseñanza de las Ciencias, v. 2, n.2, 2003. 
FAGUNDES, S.; PICCINI, I.; LAMARQUE, T.; TERRAZZAN, E. Produções em educação em ciências sob a perspectiva cts/ctsa. VII Enpec- Encontro Nacional de Pesquisas em Educação em Ciências, 2009 - Florianópolis/SC posgrad.fae.ufmg.br/posgrad/viienpec/pdfs/1120. Acesso em 20/03/2019.

KRASILCHIK, M.; MARANDINO, M. Ensino de ciências e Cidadania. São Paulo: Moderna, 2004.

LORENZETTI, L.; DELIZOICOV, D. Alfabetização científica no contexto das séries iniciais. Ensaio - Pesquisa em Educação em Ciências, Belo Horizonte, v. 3, n. 1, jun., p. 1-17, 2001.

MINISTÉRIO DA EDUCAÇÃO E CULTURA DO BRASIL. Resolução/CD/FNDE, n. 003, 21 de fevereiro de 2001. http://www.fnde.gov.br/ - Acesso em 05/12/2017.

MORAN, J. Ensino e aprendizagem inovadores com tecnologias audiovisuais e telemáticas. In: MORAN, J.; MASETTO, M.; BEHRENS, M. Novas Tecnologias e mediação Pedagógica. Campinas: Papirus, 2000.

SANTOS, W. Educação científica humanística em uma perspectiva Freireana: resgatando a função do ensino CTS. Alexandria, v. 1, n.1, p. 109-131, 2008.

SASSERON, L.; CARVALHO, A. Alfabetização científica: uma revisão bibliográfica. Investigações em Ensino de Ciências, Porto Alegre, v. 16, n. 1, p. 59-77, 2011.

SCHNORR, S.; RODRIGUES, C. Ciência, tecnologia e sociedade: ensino de Ciências no referencial pós-estruturalista. Filosofia e Educação [RFE], v.9, n. 3, Campinas, SP Outubro de 2017-Janeiro de 2018 - ISSN 1984-9605 - p. 46-75 https://www.researchgate.net/publication/321891896. Acesso 03/02/2019.

SOLIGO, M. G.; MACIEL, M.; GUAZZELLI, I. Importância de se levar em consideração as interações de alunos adolescentes com a mídia televisiva e redes sociais para uma 
proposta de ACT de cunho CTS. Revista de Ensino de Ciências e Matemática, v. 3, n. 3, p. 269-281, 2012.

TEIXEIRA, P. Movimento CTS e suas proposições para o ensino de ciências. In: . (Org.). Temas emergentes em educação científica. Vitória da Conquista: Edições UESB, 2003.

VASCONCELOS, S. SOUTO, E. O livro didático de ciências no ensino fundamental proposta de critérios para análise do conteúdo zoológico. Ciência \& Educação, v. 9, n. 1, p. 93-104, 2004. http://www.scielo.br/pdf/ciedu/v9n1/08.pdf. Acesso em 20/11/2018.

VIECHENESKI, J. Sequência didática para o ensino de ciências nos anos iniciais: subsídios teórico-práticos para a iniciação à alfabetização científica. 2013. 170 f. Dissertação (Mestrado em Ciência e Tecnologia) - Universidade Tecnológica Federal do Paraná, Ponta Grossa, 2013.

ZABALA, A. A prática educativa. Como ensinar. Porto Alegre: Arte Médicas, 1998.

\section{ANEXO}

SEQUÊNCIA DIDÁTICA

Disciplina: Ciências

Ano/Turma: $1^{\circ}$ Ano do Ensino Fundamental - Anos Iniciais

Tema: MEU CORPO PERCEBE - Identificando objetos pelo Tato

Objetivos: Reconhecer a pele como órgão do sentido, estabelecendo a relação do tato e a percepção com o ambiente e possíveis perigos que o cercam.

Relação com o BNCC: (EFI C101) Comparar características de diferentes materiais presentes em objetos do cotidiano. 
Tempo de Aplicação da Sequência Didática: 4 aulas de 50 minutos.

Organização da Classe: Grupo de 06 crianças

Recurso material: algodão, folhas de plantas frescas, areia, lixas, plástico bolha, esponjas, lã, velcro, bolsa térmica gelada e quente, sacos pretos de tecido, placas de MDF entre outros materiais à medida que outros questionamentos durante a atividade aconteçam.

- Filmes sobre os 5 sentidos do youtube

- Filme Divertida Mente (editado)

$1^{\mathrm{a}}$ aula -50 minutos

1 - Organização dos alunos conforme os grupos

2o - Levantamento dos conhecimentos prévios

3o - Problematizando:

- Me diga agora qual a textura de sua roupa (calça, blusa, meia...)?

- Qual a parte de seu corpo que você sente que a água está quente ou fria?

- É possível reconhecer objetos apenas pelo tato?

- Uma blusa mais grossa e mais quente do que uma blusa mais fina? E a blusa que esquenta?

4 - Conduzir as respostas e anotar na lousa, promovendo o reconhecimento da pele como órgão do sentido e este como forma de identificar possíveis perigos existente nos diversos ambientes que se frequenta.

\section{$2^{\mathrm{a}}$ Aula de 50 minutos}

1ㅇ - Retomar a aula anterior, passar nos grupos, os sacos pretos de tecido, com os materiais listados; 
20 - Pedir para que cada aluno em sua vez, coloque a mão dentro do saco e sinta a textura do objeto e fale o que é, retire, passe para o colega que deve repetir o procedimento ao término dos objetos, dizer se houve acerto que critério usou para identificá-los;

3-- Utilizar os filmes sobre "Os sentidos" dos endereços eletrônicos abaixo, promover uma retomada do conteúdo trabalhado anteriormente e introduzir novas informações na lousa, tendo em vista as discussões da aula anterior;

www.youtube.com/watch?v=ezwz8TBcjYo

www.youtube.com/watch?v=da-CT-Pw3uw

4-- Ao término dos filmes, solicitar o desenho dos objetos que estavam no saco nomeando e dando suas características;

\section{3ำ Aula de 50 minutos}

10 - Projeção do filme Divertidamente no seguinte site: https://www.omelete.com.br/humor e fazer uma discussão entre as emoções da protagonista e as emoções que sentimento no cotidiano.

(Sinopse do filme "Divertidamente", da Pixar, mostra um olhar fantasioso (e cientificamente baseado) sobre como nossas emoções e memórias são processadas. Durante todo o filme vemos cinco dessas emoções personificadas dentro da mente da personagem principal, Riley, e dos seus pais, e como as ações dessas emoções mudam o comportamento deles).

2ㅇ - Falar sobre as percepções e sensações, questionar, levá-los a pensar sobre o assunto para posterior explicação dos conceitos e discutir em forma de simulação:

- - Como as sensações estão relacionadas ao ambiente: frio, calor, sede, medo, sono, alegria...

- $\quad$ - Formas de manifestar emoções: respiração, voz, expressões faciais, explorar o assunto 
- - Brincadeira de mímica com expressões faciais

30- Pedir para desenharem "emojis" com características de emoções (em grupo) Fazer uma roda de conversa sobre situações que se encaixam com os desenhos dos emojis.

\section{4ํㅗ Aula de 50 minutos}

1․ - Apresentação dos trabalhos em grupo: Desenhos dos objetos e dos emojis

20 - Confeccionar um livrinho do tato com placas de MDF e animais para que os alunos possam testar as diversas características de texturas, ao término os livros serão expostos na Feira do Conhecimento para que outros alunos da escola possam vê-los.

Enviado: Julho, 2019.

Aprovado: Agosto, 2019. 